\title{
Malignant MCA Infarction: Pathophysiology and Imaging for Early Diagnosis and Management Decisions
}

\author{
Wolf-Dieter Heiss \\ Max Planck Institute for Metabolism Research, Cologne, Germany
}

\section{Key Words}

Malignant MCA infarction · Ischemic tissue damage .

Penumbra - Brain edema · CT-hypodensity · DW-MRI-lesion . PET tracer accumulation - Decompressive hemicraniectomy

\begin{abstract}
Background: Malignant middle cerebral artery infarction is a devastating condition, with up to $80 \%$ mortality in conservatively treated patients. The pathophysiology of this stroke is characterized by a large core of severe ischemia and only a relatively small rim of penumbra. Due to the fast development of irreversible morphological damage, cytotoxic edema occurs immediately in a large portion of the ischemic territory. The subsequent damage of the tight junctions leads to the breakdown of the blood brain barrier and vasogenic brain edema, resulting in space-occupying brain swelling. The progressive vasogenic edema reaches its maximum after 1 to several days and exerts a mechanical force on surrounding tissue structures leading to midline shift and transtentorial herniation and finally brain stem compression and death. Summary: Early severe neurological symptoms hemiparesis, gaze deviation, higher cortical signs - followed by headache, vomiting, papillo edema and reduced con-
\end{abstract}

sciousness may predict the deleterious course. Imaging supports the suspected diagnosis with hypodense changes on CT extending beyond $50 \%$ of the MCA territory. The size of the probably infarcted tissue and a midline shift on CT as well as the size of the lesion on diffusion-weighted MRI are predictive of a malignant course. Reduction of cerebral blood flow below a critical value and volume of irreversible tissue damage detected by positron emission tomography in the early hours after the stroke are indicative of progression to malignant infarction with increased intracranial pressure (ICP) and decreased tissue oxygen tension observed by multimodal neuromonitoring in the later course. Treatment options of malignant infarction include general measures to limit the extent of space-occupying edema, but these therapies have not been efficacious. Only surgical intervention with decompressive hemicraniectomy (DHC) was successful in relieving the effects of increased ICP and of the deleterious shifts of brain tissue. Several controlled clinical trials have proven the efficacy of DHC with a significant decrease in mortality and improved functional outcome. However, DHC must be performed early and with a large diameter, regardless of the age of patients, but in patients beyond 60 years, the higher likelihood of resulting severe disability should be taken into consideration. Key Messages: Malignant MCA in-

\section{KARGER}

E-Mail karger@karger.com www.karger.com/ced
Wolf-Dieter Heiss, MD

Max Planck Institute for Metabolism Research Gleueler Str. 50, DE-50931 Cologne (Germany) E-Mailwdh@sf.mpg.de 
farction can be predicted early with a high sensitivity by neuroimaging. The early diagnosis is mandatory for $\mathrm{DHC}$, which was shown to reduce mortality and improve functional outcome in several controlled clinical trials.

(c) 2015 S. Karger AG, Basel

\section{Introduction}

Ischemia involving large portions of a hemisphere may cause space-occupying cerebral edema leading to rapid neurological deterioration. The most serious condition involving the whole territory of the middle cerebral artery was termed 'malignant MCA infarction' [1] and it manifests itself with a severe hemispheric syndrome including hemiparesis, gaze deviation and higher cortical signs combined and followed by headache, vomiting, papillo edema and reduced consciousness. The lifethreatening edema develops usually 1 to several days after the stroke and may cause midline shift, transtentorial herniation and death in up to $80 \%$ within the first week [2]. The annual incidence of this devastating condition is 10 20 per 100,000 people [3], females are more often affected and younger patients are more susceptible due to decreased potentially compensatory space within the intracranial cavity [4].

\section{Evolvement of Tissue Damage}

The energy demand of the brain is rather high and therefore sufficient blood supply must be maintained constantly. If the normal cerebral blood flow is reduced below a certain level, reversible functional failure occurs; a further decrease of CBF below a lower level leads to irreversible morphological damage [5]. The tissue with perfusion values in the range between these limits is called the 'ischemic penumbra,' which is characterized by the potential for functional recovery without morphological damage, provided that local blood flow can be reestablished within a certain time window that is dependent on the residual flow [6].

During the acute phase at flows below the threshold of energy metabolism required for maintenance of basic housekeeping ( $~ 20 \%$ of preocclusion values) in the core tissue, injury is a direct consequence of the ischemia-induced energy failure. The disturbance of the energy-dependent ionic pumps leads to increase in intracellular sodium and extracellular potassium concentrations as well as calcium influx into cells. With the disturbed ionic equi- librium, water is transported into the cells causing osmotic swelling. The final result is terminal depolarization of cell membranes; it is established within a few minutes after the onset of severe ischemia.

During the subsequent subacute phase, the irreversible damage expands into the areas around the core where flow ranges between 25 and $35 \%$ of preocclusion values until after several hours (usually approximately $6 \mathrm{~h}$ ) the lesion has extended over all the area with critically reduced blood supply. A multitude of electrical and biological disturbances interact in the progression of irreversible cell damage in ischemia (review in [7]); peri-infarct spreading depression like depolarization play an important role in triggering and continuously stimulating this molecular/biochemical cascade of cell injury (reviews in [8]) and contribute to the growth of the infarct. Most of the biochemical and molecular processes suspected as potential key factors in the propagation of ischemic damage (review in [7]) still cannot be assessed in humans.

The transfer of the concept of the penumbra and of the progression of ischemic damage into imaging modalities is difficult, as most markers used in experimental studies necessitate invasive procedures. In order to follow these pathophysiologic changes, noninvasive imaging modalities are required, which provide quantitative maps of several important physiologic variables, including regional cerebral blood flow (rCBF), regional cerebral blood volume and regional cerebral metabolic rate of oxygen and glucose, and up to now only positron emission tomography (PET) is able to measure these variables repeatedly. Early PET studies in stroke have identified various tissue compartments within a brain territory compromised by ischemia (review in [9]). These PET studies allow the classification of 3 regions within the disturbed vascular territory: the core of ischemia with a flow $<12 \mathrm{ml} / 100 \mathrm{~g} / \mathrm{min}$ usually showing a transition into necrosis; a penumbra region with a flow between 12 and $22 \mathrm{ml} / 100 \mathrm{~g} / \mathrm{min}$ of still viable tissue but with uncertain chances for infarction or recovery; and a hypoperfused area ( $>22 \mathrm{ml} / 100 \mathrm{~g} / \mathrm{min}$ ) not primarily damaged by the lack of blood supply. It has to be kept in mind that the condition of the tissue is changing with time; the extent of the penumbra and its conversion into infarction is a dynamic process, and irreversible damage spreads from the core of ischemia to its border.

Finally, a delayed phase of tissue injury evolves, which may last for several days or even weeks, in which secondary phenomena - vasogenic edema, inflammation, programmed cell death - may contribute to further progression of tissue damage. 


\section{Brain Edema}

Ischemic brain edema can be differentiated into 2 pathophysiologically different types: an early cytotoxic type, followed after some delay by a late vasogenic type of edema. The cytotoxic type of edema is initiated at flow values close to $30 \%$ of control when stimulation of anaerobic metabolism causes an increase of brain tissue osmolality and, hence, an osmotically obliged cell swelling. At flow values below $20 \%$ of control, failure of the $\mathrm{Na}+/$ $\mathrm{K}+$ pump leads to an influx of $\mathrm{Na}+$ and progressive loss of the ionic gradient, resulting in membrane depolarization further enhancing intracellular osmolality and the associated cell swelling. In the absence of blood flow, cell swelling occurs at the expense of the extracellular fluid volume, leading to the shrinkage of the extracellular compartment, but not to a change in the net water content. The shift of fluid is reflected by a decrease of the apparent diffusion coefficient (ADC) of water, which is the reason for the increase of signal intensity in diffusionweighted MRI (DW-MRI) [10]. However, if some residual blood flow persists, water is taken up from the blood and the net tissue water content increases. After vascular occlusion, this increase starts within a few minutes after the onset of ischemia and it causes a gradual increase in brain volume.

With the evolution of tissue necrosis and the degradation of basal lamina, the blood-brain barrier breaks down [11], and after 4-6 h, serum proteins begin to leak from the blood into the brain. This disturbance initiates a vasogenic type of edema, which further enhances the water content of the tissue. The exact mechanism through which ischemic injury disrupts the BBB is not fully understood, though active pinocytosis by endothelial cells appears to occur early, with the disruption of the tight junctions becoming a later feature [12]. Additionally, several ischemia-induced mediators including matrix metalloproteinases, nitric oxide synthase, vascular endothelial growth factors and thrombin might be involved. Reestablishment of recirculation in areas of the infarcted tissue might contribute to the flow of water through the ruptured blood-brain barrier [13]. Vasogenic edema reaches its peak at 1 to several days after the onset of ischemia and may cause an increase of tissue water by more than $100 \%$. Vasogenic edema, in contrast to the early cytotoxic type of edema, is isoosmotic and accumulates mainly in the extracellular compartment. This reverses the narrowing of the extracellular space and explains the 'pseudonormalisation' of the signal intensity observed in DW-MRI [14]. However, as the total tissue water content is in- creased at this time, the high signal intensity in T2weighted images clearly differentiates this situation from a 'real' recovery to normal.

Progressive brain edema following ischemic stroke exerts a mechanical force on surrounding tissue structures. This occurs within the fixed volume of the intracranial cavity, and is therefore at the expense of other compartments, namely the vasculature and cerebrospinal fluid space. Once accommodative mechanisms are exhausted, intracranial pressure (ICP) starts to rise. Consequently, cerebral blood flow is compromised, with failure of autoregulation and worsening ischemia. Rising ICP may then result in tissue shifts, with midline shift and transtentorial and uncal herniation leading to progressive brainstem dysfunction.

\section{Imaging}

Imaging plays a central role in the prediction of the development of malignant infarctions and is essential for early therapeutic interventions (reviews $[4,15]$ ).

\section{CT}

In most institutions, $\mathrm{CT}$ is the first diagnostic procedure performed in acute stroke and is essential for the differentiation of ischemia from other causes. Within the first few hours after onset of symptoms, CT shows attenuation changes within the grey matter resulting in the loss of grey-white matter differentiation at the cortex, loss of distinction of basal ganglia and of the insular ribbon. With development of early edema, cortical sulci disappear and hypo-attenuation develops in the white matter. An extension of these early hypodense changes beyond $50 \%$ of the MCA territory predicted malignant infarction with a sensitivity of $61 \%$ and a specificity of $94 \%[16,17]$. An infarct volume of $>220 \mathrm{ml}$ as well as midline shift of $>3.9 \mathrm{~mm}$ were predictive of severe brain edema and herniation [18]. The risk of malignant course can be estimated by ASPECTS (Alberta Stroke Program Early CT score), where 7 was the cutoff score to determine progression to malignant infarction with $50 \%$ sensitivity and $86 \%$ specificity [19]. On CT-perfusion (PCT) maps the early involvement of more than two thirds of the MCA territory predicted malignant course with high sensitivity (92\%) and specificity (94\%) [20]. PCT can also assess increased blood-brain-barrier permeability, which leads to malignant infarction [21]. The involvement of additional vas- 
cular territories $[22,23]$ and carotid occlusion [24] additionally predicted a fatal outcome. The extent of collateral circulation to the ischemic territory can be analyzed by CT angiography: a collateral score of less than 2 derived from these images was shown to be an independent predictor of malignant brain edema in addition to an NIHSS score of $>18$ [25].

\section{MRI}

MRI, especially diffusion-weighted imaging (DWI), is more sensitive than CT for the early detection of ischemic lesions. A DWI lesion volume of $145 \mathrm{ml}$ was predictive of malignant infarction (100\% sensitivity, $94 \%$ specificity) [26], but the determination of this cortical volume is dependent on the threshold of the reduction of the ADC used for DWI evaluation: using an ADC cutoff value of $80 \%$ compared to contralateral healthy tissue, a volume of $>82 \mathrm{ml}$ within $6 \mathrm{~h}$ of symptoms onset predicted malignant infarction with high specificity $(98 \%)$ but low sensitivity (52\%) [27]. Follow-up examination after $24 \mathrm{~h}$ improves sensitivity to $79 \%$, while specificity-positive predictive value and negative predictive value remained unchanged [28]. The addition of a measure for brain atrophy could further increase the positive predictive value of the DWI lesion size [29].

\section{Imaging of Flow and Tissue Viability}

Quantitative measures of cerebral blood flow might be used to determine the critical thresholds of ischemia and the size of developing infarcts. Early single photon emission computed tomography (SPECT) with 99m-technetium-ethyl-cysteinate predicted malignant MCA infarction more accurately than CT changes or clinical symptoms [30]. PET of 11C-flumazenil (FMZ) can be used to assess rCBF (early distribution) and irreversible neuronal damage (reduced tracer accumulation). In 34 patients with ischemic changes in $>50 \%$ of the MCA territory in early CT scans, results of FMZ-PET performed within $24 \mathrm{~h}$ after stroke were compared with recordings from probes of tissue oxygen pressure, ICP and microdialysis placed into the ipsilateral frontal cortex [31]. The early PET measurements demonstrated larger volumes of ischemic core (mean 144.5 vs. $62.2 \mathrm{ml}$ ) and of irreversibly damaged tissue ( 157.9 vs. $47.0 \mathrm{ml}$ ) in patients with malignant course (i.e. progressive edema formation with midline shift) than in patients with benign course. Mean ce- rebral blood flow values within the ischemic core were significantly lower and the volume of the ischemic penumbra was smaller in the malignant than in the benign group. In patients with malignant course, cerebral perfusion pressure dropped to $<50 \mathrm{~mm} \mathrm{Hg} 52 \mathrm{~h}$ (mean) after onset of symptoms; subsequently, tissue oxygen pressure dropped and glutamate increased, indicating secondary ischemia responsible for extension of infarction. These findings indicate that PET studies could be used to predict the development of malignant infarction, whereas multimodal neuromonitoring detects secondary infarction of peri-infarct tissue once it occurs.

PET and SPECT studies help to determine thresholds for tissue viability and to elucidate pathophysiological changes leading to space-occupying infarction, but are not suited for the selection of patients for invasive treatment in the clinical setting. Therefore, the selection of patients for surgical therapy is based on CT (infarction $>50 \%$ of MCA territory, ASPECT score 7 or lower, PCT deficit in 2/3 of MCA territory) or MRI (DWI total lesion volume of $>145 \mathrm{ml}$ or cortical lesion volume of $>82 \mathrm{ml}$ within $6 \mathrm{~h}$ ).

\section{Treatment}

Recently, guidelines for the management of patients with malignant MCA infarction were published [4, 15], and therefore, only recent advances in the therapy of malignant infarction are reviewed in the following. Of the general conservative measures, only hypothermia showed some beneficial effects: hypothermia reduces postischemic hyperperfusion, delayed postischemic hypoperfusion, blood brain barrier disruption, brain edema and volume of neuronal damage after focal cerebral ischemia in animal models [32]. In patients with malignant MCA infarction, maintaining core temperature at $33^{\circ} \mathrm{C}$ for $48-$ $72 \mathrm{~h}$ reduced mortality to $44 \%$ with an outcome on Barthel Index of 70 at 3 months [33]. In comparison to decompressive hemicraniectomy (DHC), hypothermia is less effective: mortality with hypothermia was $47 \%$ compared to $12 \%$ with DHC [34]. In combination with hemicraniectomy, hypothermia may have an additional beneficial effect (slightly improved outcome after 6 months without additional side effects) [35], but a controlled study is still in progress [36].

Osmotic therapy is used to reduce existing edema and minimize tissue shifts, but studies with hypertonic saline solutions, mannitol and glycerol, which all were effective in reducing at least transiently intracranial pressure, did 
not significantly improve outcome [37-39]. Also, steroids failed to improve functional outcome or reduce mortality [40]. However, osmotherapy may be beneficial to bridge the time to surgical intervention.

\section{DHC}

The consequences of space occupying edema due to malignant infarction with shift of tissue to the contralateral side (midline shift), to the posterior fossa (tentorial herniation) and finally leading to compression of the brain stem and death can be mitigated only by creating additional space for the edematous brain to expand by DHC. After the first description of the effect of this procedure [41], numerous case reports and case series have indicated potential benefits especially with respect to survival rates in patients with malignant infarction (reviews in $[4,15,42,43])$. Based on these results, several prospective randomized trials were performed [44-46], which taken alone did not result in significantly improved clinical outcome. A pooled analysis of these 3 trials provided evidence that $\mathrm{DHC}$ is a life-saving procedure, increasing the chances of survival from 29 to $78 \%$ [47], but an improvement in functional outcome of survivors (dichotomized to mRS 0-3 vs. 4-6) was not observed. This poor clinical outcome with increased survival rates was especially demonstrated in patients beyond the age of 60: decrease in mortality rate from $70 \%$ in control patients to $33 \%$ in DHC, but survival with poor neurological status (mRS4 32 vs. $15 \%, 28$ vs. $13 \%$ mRS5, only 7 vs. $3 \%$ for mRS3) [48]. Similar results were observed in a nationwide survey of DHC in Japan [49]. However, contrary to expectations, DHC in the dominant hemisphere was not associated with worse outcomes $[42,50]$. It was shown repeatedly that early DHC performed within $24 \mathrm{~h}$ after onset of symptoms significantly reduced mortality and improved outcome 6 and 12 months after stroke [44, 45]. DHC performed $48 \mathrm{~h}$ after stroke onset might not have a beneficial effect on mortality or clinical outcome [51]. Additionally, the size of the hemicraniectomy is important and a diameter of DHC of at least $12 \mathrm{~cm}$ is recommended in most studies. Pre- and postoperative perfusion CT hemodynamic parameters were associated with mortality and the improvement of PCT parameters after DHC was related to favorable outcome [52]. Recent metaanalyses including newer controlled trials $[51,53,54]$ confirmed the results of previous studies: DHC significantly decreases mortality and improves functional outcome for malignant infarction in patients aged 18-80, although with a nonsignificant increase in the proportion of major disability especially among aged survivors. Therefore, DHC should be recommended to improve survival after malignant infarction regardless of patient age, but in patients older than 60 years, the wishes of patients and family should be taken into consideration, since the likelihood of resulting severe disability is rather high. Improved imaging procedures - perfusion and angio CT, PW and DW-MRI, PET - early after stroke may help to select patients who will develop malignant infarction and therefore will especially benefit from early DHC. Controlled studies to prove this concept and the effect on hemodynamic parameters [52] are urgently needed.

\section{Disclosure Statement}

None.

\section{References}

1 Hacke W, Schwab S, Horn M, Spranger M, De Georgia M, von Kummer R: 'Malignant' middle cerebral artery territory infarction: clinical course and prognostic signs. Arch Neurol 1996;53:309-315.

2 White OB, Norris JW, Hachinski VC, Lewis A: Death in early stroke, causes and mechanisms. Stroke 1979;10:743.

3 Bounds JV, Wiebers DO, Whisnant JP, Okazaki $\mathrm{H}$ : Mechanisms and timing of deaths from cerebral infarction. Stroke 1981;12:474477.

4 Treadwell SD, Thanvi B: Malignant middle cerebral artery (MCA) infarction: pathophysiology, diagnosis and management. Postgrad Med J 2010;86:235-242.
5 Astrup J, Siesjö BK, Symon L: Thresholds in cerebral ischemia - the ischemic penumbra. Stroke 1981;12:723-725.

6 Heiss WD, Rosner G: Functional recovery of cortical neurons as related to degree and duration of ischemia. Ann Neurol 1983;14:294-301.

7 Hossmann KA: Pathophysiology and therapy of experimental stroke. Cell Mol Neurobiol 2006;26:1057-1083.

8 Lauritzen M, Dreier JP, Fabricius M, Hartings JA, Graf R, Strong AJ: Clinical relevance of cortical spreading depression in neurological disorders: migraine, malignant stroke, subarachnoid and intracranial hemorrhage, and traumatic brain injury. J Cereb Blood Flow Metab 2011;31:17-35.
9 Heiss WD: David Sherman lecture 2012: the role of positron emission tomography for translational research in stroke. Stroke 2012; 43:2520-2525.

10 Hoehn-Berlage M, Norris DG, Kohno K, Mies G, Leibfritz D, Hossmann KA: Evolution of regional changes in apparent diffusion coefficient during focal ischemia of rat brain: the relationship of quantitative diffusion NMR imaging to reduction in cerebral blood flow and metabolic disturbances. J Cereb Blood Flow Metab 1995; 15:10021011.

11 Wang CX, Shuaib A: Critical role of microvasculature basal lamina in ischemic brain injury. Prog Neurobiol 2007;83:140-148. 
12 Kniesel U, Wolburg H: Tight junctions of the blood-brain barrier. Cell Mol Neurobiol 2000; 20:57-76.

13 Nielsen TH, Stahl N, Schalen W, Reinstrup P, Toft P, Nordstrom CH: Recirculation usually precedes malignant edema in middle cerebral artery infarcts. Acta Neurol Scand 2012;126: 404-410.

14 Lansberg MG, Thijs VN, O’Brien MW, Ali JO, de Crespigny AJ, Tong DC, Moseley ME, Albers GW: Evolution of apparent diffusion coefficient, diffusion-weighted, and T2-weighted signal intensity of acute stroke. AJNR Am J Neuroradiol 2001;22:637-644.

15 Torbey MT, Bosel J, Rhoney DH, Rincon F, Staykov D, Amar AP, Varelas PN, Juttler E, Olson D, Huttner HB, Zweckberger K, Sheth KN, Dohmen C, Brambrink AM, Mayer SA, Zaidat OO, Hacke W, Schwab S: Evidencebased guidelines for the management of large hemispheric infarction: a statement for health care professionals from the neurocritical care society and the German society for neuro-intensive care and emergency medicine. Neurocrit Care 2015;22:146-164.

16 von Kummer R, Meyding-Lamade U, Forsting M, Rosin L, Rieke K, Hacke W, Sartor K: Sensitivity and prognostic value of early CT in occlusion of the middle cerebral artery trunk. AJNR Am J Neuroradiol 1994;15:9-15; discussion 16-18.

17 Krieger DW, Demchuk AM, Kasner SE, Jauss M, Hantson L: Early clinical and radiological predictors of fatal brain swelling in ischemic stroke. Stroke 1999;30:287-292.

18 Park J, Goh DH, Sung JK, Hwang YH, Kang DH, Kim Y: Timely assessment of infarct volume and brain atrophy in acute hemispheric infarction for early surgical decompression: strict cutoff criteria with high specificity. Acta Neurochir (Wien) 2012;154:79-85.

19 MacCallum C, Churilov L, Mitchell P, Dowling R, Yan B: Low alberta stroke program early CT score (ASPECTS) associated with malignant middle cerebral artery infarction. Cerebrovasc Dis 2014;38:39-45.

20 Ryoo JW, Na DG, Kim SS, Lee KH, Lee SJ, Chung CS, Choi DS: Malignant middle cerebral artery infarction in hyperacute ischemic stroke: evaluation with multiphasic perfusion computed tomography maps. J Comput Assist Tomogr 2004;28:55-62.

21 Foerch C, Lang JM, Krause J, Raabe A, Sitzer M, Seifert V, Steinmetz H, Kessler KR: Functional impairment, disability, and quality of life outcome after decompressive hemicraniectomy in malignant middle cerebral artery infarction. J Neurosurg 2004;101:248-254.

22 Kasner SE, Demchuk AM, Berrouschot J, Schmutzhard E, Harms L, Verro P, Chalela JA, Abbur R, McGrade H, Christou I, Krieger DW: Predictors of fatal brain edema in massive hemispheric ischemic stroke. Stroke 2001;32:2117-2123.

23 Lee SJ, Lee KH, Na DG, Byun HS, Kim YB, Shon YM, Cho SJ, Lee J, Chung CS, Hong SC: Multiphasic helical computed tomography predicts subsequent development of severe brain edema in acute ischemic stroke. Arch Neurol 2004;61:505-509.

24 Kucinski T, Koch C, Grzyska U, Freitag HJ, Kromer $\mathrm{H}$, Zeumer $\mathrm{H}$ : The predictive value of early CT and angiography for fatal hemispheric swelling in acute stroke. AJNR Am J Neuroradiol 1998;19:839-846.

25 Kim H, Jin ST, Kim YW, Kim SR, Park IS, Jo KW: Predictors of malignant brain edema in middle cerebral artery infarction observed on CT angiography. J Clin Neurosci 2015;22: 554-560.

26 Oppenheim C, Samson Y, Manai R, Lalam T, Vandamme X, Crozier S, Srour A, Cornu P, Dormont D, Rancurel G, Marsault C: Prediction of malignant middle cerebral artery infarction by diffusion-weighted imaging. Stroke 2000;31:2175-2181.

27 Thomalla G, Hartmann F, Juettler E, Singer OC, Lehnhardt FG, Kohrmann M, Kersten JF, Krutzelmann A, Humpich MC, Sobesky J, Gerloff C, Villringer A, Fiehler J, NeumannHaefelin T, Schellinger PD, Rother J; Clinical Trial Net of the German Competence Network Stroke: Prediction of malignant middle cerebral artery infarction by magnetic resonance imaging within 6 hours of symptom onset: a prospective multicenter observational study. Ann Neurol 2010;68:435-445.

28 Kruetzelmann A, Hartmann F, Beck C, Juettler E, Singer OC, Kohrmann M, Kersten JF, Sobesky J, Gerloff C, Villringer A, Fiehler J, Neumann-Haefelin T, Schellinger PD, Rother J, Thomalla G; Clinical Trial Net of the German Competence Network Stroke: Combining magnetic resonance imaging within six-hours of symptom onset with clinical follow-up at $24 \mathrm{~h}$ improves prediction of 'malignant' middle cerebral artery infarction. Int J Stroke 2014;9:210-214.

29 Beck C, Kruetzelmann A, Forkert ND, Juettler E, Singer OC, Kohrmann M, Kersten JF, Sobesky J, Gerloff C, Fiehler J, Schellinger PD, Rother J, Thomalla G: A simple brain atrophy measure improves the prediction of malignant middle cerebral artery infarction by acute DWI lesion volume. J Neurol 2014;261: 1097-1103.

30 Berrouschot J, Barthel H, von Kummer R, Knapp WH, Hesse S, Schneider D: 99m technetium-ethyl-cysteinate-dimer single-photon emission CT can predict fatal ischemic brain edema. Stroke 1998;29:2556-2562.

31 Dohmen C, Bosche B, Graf R, Staub F, Kracht L, Sobesky J, Neveling M, Brinker G, Heiss WD: Prediction of malignant course in MCA infarction by PET and microdialysis. Stroke 2003;34:2152-2158.

32 Karibe H, Zarow GJ, Graham SH, Weinstein PR: Mild intraischemic hypothermia reduces postischemic hyperperfusion, delayed postischemic hypoperfusion, blood-brain barrier disruption, brain edema, and neuronal damage volume after temporary focal cerebral ischemia in rats. J Cereb Blood Flow Metab 1994; 14:620-627.
33 Schwab S, Schwarz S, Spranger M, Keller E, Bertram M, Hacke W: Moderate hypothermia in the treatment of patients with severe middle cerebral artery infarction. Stroke 1998;29: 2461-2466.

34 Georgiadis D, Schwarz S, Aschoff A, Schwab $S:$ Hemicraniectomy and moderate hypothermia in patients with severe ischemic stroke. Stroke 2002;33:1584-1588.

35 Els T, Oehm E, Voigt S, Klisch J, Hetzel A, Kassubek J: Safety and therapeutical benefit of hemicraniectomy combined with mild hypothermia in comparison with hemicraniectomy alone in patients with malignant ischemic stroke. Cerebrovasc Dis 2006;21:79-85.

36 Neugebauer H, Kollmar R, Niesen WD, Bosel J, Schneider H, Hobohm C, Zweckberger K, Heuschmann PU, Schellinger PD, Juttler E; DEPTH-SOS Study Group; IGNITE Study Group: DEcompressive surgery Plus hypoTHermia for Space-Occupying Stroke (DEPTH-SOS): a protocol of a multicenter randomized controlled clinical trial and a literature review. Int J Stroke 2013;8:383-387.

37 Bereczki D, Fekete I, Prado GF, Liu M: Mannitol for acute stroke. Cochrane Database Syst Rev 2007;3:CD001153.

38 Righetti E, Celani MG, Cantisani T, Sterzi R, Boysen G, Ricci S: Glycerol for acute stroke. Cochrane Database Syst Rev 2004;2: CD000096.

39 Hauer EM, Stark D, Staykov D, Steigleder T, Schwab S, Bardutzky J: Early continuous hypertonic saline infusion in patients with severe cerebrovascular disease. Crit Care Med 2011;39:1766-1772.

40 Qizilbash N, Lewington SL, Lopez-Arrieta JM: Corticosteroids for acute ischaemic stroke. Cochrane Database Syst Rev 2002;2:CD000064.

41 Scarcella G: Encephalomalacia simulating the clinical and radiological aspects of brain tumor; a report of 6 cases. J Neurosurg 1956;13: 278-292.

42 Gupta R, Connolly ES, Mayer S, Elkind MS: Hemicraniectomy for massive middle cerebral artery territory infarction: a systematic review. Stroke 2004;35:539-543.

43 Neugebauer H, Juttler E: Hemicraniectomy for malignant middle cerebral artery infarction: current status and future directions. Int J Stroke 2014;9:460-467.

44 Vahedi K, Vicaut E, Mateo J, Kurtz A, Orabi M, Guichard JP, Boutron C, Couvreur G, Rouanet F, Touze E, Guillon B, Carpentier A, Yelnik A, George B, Payen D, Bousser MG; DECIMAL Investigators: Sequential-design, multicenter, randomized, controlled trial of early decompressive craniectomy in malignant middle cerebral artery infarction (DECIMAL trial). Stroke 2007;38:2506-2517.

45 Juttler E, Schwab S, Schmiedek P, Unterberg A, Hennerici M, Woitzik J, Witte S, Jenetzky E, Hacke W; DESTINY Study Group: Decompressive surgery for the treatment of malignant infarction of the middle cerebral artery (DESTINY): a randomized, controlled trial. Stroke 2007;38:2518-2525. 
46 Hofmeijer J, Kappelle LJ, Algra A, Amelink GJ, van Gijn J, van der Worp HB; HAMLET Investigators: Surgical decompression for space-occupying cerebral infarction (the hemicraniectomy after middle cerebral artery infarction with life-threatening edema trial [HAMLET]): a multicentre, open, randomised trial. Lancet Neurol 2009;8:326-333.

47 Vahedi K, Hofmeijer J, Juettler E, Vicaut E, George B, Algra A, Amelink GJ, Schmiedeck P, Schwab S, Rothwell PM, Bousser MG, van der Worp HB, Hacke W; DECIMAL, DESTINY, and HAMLET Investigators: Early decompressive surgery in malignant infarction of the middle cerebral artery: a pooled analysis of three randomised controlled trials. Lancet Neurol 2007;6:215-222.

48 Juttler E, Unterberg A, Woitzik J, Bosel J, Amiri H, Sakowitz OW, Gondan M, Schiller
P, Limprecht R, Luntz S, Schneider H, Pinzer T, Hobohm C, Meixensberger J, Hacke W; DESTINY II Investigators: Hemicraniectomy in older patients with extensive middle-cerebral-artery stroke. N Engl J Med 2014;370: 1091-1100.

49 Suyama K, Horie N, Hayashi K, Nagata I: Nationwide survey of decompressive hemicraniectomy for malignant middle cerebral artery infarction in Japan. World Neurosurg 2014; 82:1158-1163.

50 Weil AG, Rahme R, Moumdjian R, Bouthillier A, Bojanowski MW: Quality of life following hemicraniectomy for malignant MCA territory infarction. Can J Neurol Sci 2011;38: 434-438.

51 Lu X, Huang B, Zheng J, Tao Y, Yu W, Tang L, Zhu R, Li S, Li L: Decompressive craniectomy for the treatment of malignant infarc- tion of the middle cerebral artery. Sci Rep 2014;4:7070.

52 Amorim RL, de Andrade AF, Gattas GS, Paiva WS, Menezes M, Teixeira MJ, Bor-Seng-Shu E: Improved hemodynamic parameters in middle cerebral artery infarction after decompressive craniectomy. Stroke 2014;45:13751380.

53 Yang MH, Lin HY, Fu J, Roodrajeetsing G, Shi SL, Xiao SW: Decompressive hemicraniectomy in patients with malignant middle cerebral artery infarction: a systematic review and meta-analysis. Surgeon 2015;13:230240.

54 Back L, Nagaraja V, Kapur A, Eslick GD: Role of decompressive hemicraniectomy in extensive middle cerebral artery strokes: a metaanalysis of randomised trials. Intern Med J 2015;45:711-717. 